\title{
Preparation and Properties of PLA/clay composites
}

\author{
Hongjuan ZHENG ${ }^{1,}$, , Zhengqian SUN ${ }^{2, b}$ \\ 1Department of Material Science and Engineering, Henan University of Technology, Zhengzhou, \\ 450001, China \\ 2Department of Material Science and Engineering, Henan University of Technology, Zhengzhou, \\ 450001, China \\ aemail: zhj6287@163.com, bemail:420128326@qq.com
}

Keywords: Ploylactic acid; Clay; Surface treatment agent; Composites; Properties

\begin{abstract}
In order to improve the toughness, thermal property and impact resistance of PLA, clay modified with different surface treatment agents (titanium ester, silane coupling agent and alkylamine) was added to PLA matrix. The samples were examined by fourier transform infrared (FT-IR) spectroscopy, micropolariscopy and mechanical properties thermogravimetric analysis, differential scanning calorimetry(DSC). The results show that titanium ester's modification works best. The thermal resistance and crystallinity were improved, the tensile strength reached 61.2MPa, increasing by $20.0 \%$ compared to unprocessed materials and $26.7 \%$ in comparison to pure PLA.
\end{abstract}

\section{Introduction}

PLA is biodegradable plastics which produced by acid molecules from renewable resources[1-2]. It is a non-toxic, non stimulating[3], excellent mechanical properties, biocompatibility and biodegradable environmentally friendly polymer [4].However, Some shortcomings of PLA limit its application, such as the hydrophobicity, soft toughness, the poor mechanical property, heat resistance and crystallization rate [5-7]. So it is often used to improve the application range of PLA by modification, and the modification aims to modify PLA by means of copolymerization, blend, surface treatment, plasticizer,inorganic complex and so on[8-9]. The structure, properties and applications of PLA/layered silicate composites are relatively conspicuous, so it has become a hot topic in the research of polymer materials[10].

Clay is a mixture of various minerals, and its particle size is mostly less than $2 \mathrm{um}[11]$, and it is also one of the most commonly used in the preparation of poly lactic acid/layered silicate composites. By appropriate processing methods, the molecular chain can insert into the interlayers of layered silicate, so that the lamellar clay dissection occurred. Small scales dispersed in poly (lactic acid) matrix, its mechanical properties, thermal properties and melt strength would obtain different degrees of improvement[12-13].

The surface modification of clay can increase interlayer spacings, and the hydrophilic clay has better compatibility hydrophobic polymer molecules, an intercalated or partially exfoliated composite is formed, and the performance of the PLA/clay compositesc can be improved effectively.

\section{Experimental}

According to the literatures[7,14,15], Clay with $3 \mathrm{wt} \%$ content was modified by different surface treatment agents (titaniumester, silane coupling agent and alkylamine ). Then the mixture was added to the PLA matrix and mixed them uniformly.The mixture with well dispersion was melt blended by using Su-70 internal mixer with a mixing time of $5 \mathrm{~min}, 20 \mathrm{rpm}$ at $180^{\circ} \mathrm{C}$. Then the mixture was pressed into sheet on XLB-400x400 vulcanizing machine at $180^{\circ} \mathrm{C}$ for $5 \mathrm{~min}$. After being cooled to room temperature, the sheet was processed into standard bars.

The tensile strength and elongation at break of the standard samples were examined on WDW-S5 tensile-testing machine under the stretching rate of $10 \mathrm{~mm} / \mathrm{min}$. The flowability of the 
samples were investigated at $200^{\circ} \mathrm{C}$ by SRD-400D melt flow indexer. The Fourier Transform Infrared (FT-IR) Spectroscopy was measured with IRPESTIGE-21 IR Spectrum Scanner (Shimadzu, Japan). The structure and the morphology of the samples after melt blending were observed by XSZ-H7 micropolariscope. The thermal stability have been studied by DSC and TG techniques.

\section{Results and discussion}

Table. 1 shows that the mechanical properties of PLA/Clay composites modified by different surface treatment agents (titanium ester, silane coupling agent and alkylamine ) before being mixed with PLA matrix.

Table1 Effects of different surface treatment agents on mechanical properties of PLA/Clay composites

\begin{tabular}{|c|c|c|c|c|}
\hline Types & $\begin{array}{c}\text { No treatment } \\
\text { agent }\end{array}$ & Alkylamine & $\begin{array}{c}\text { Silane coupling } \\
\text { agent }\end{array}$ & Titanium ester \\
\hline $\begin{array}{c}\text { Tensile } \\
\text { strength(MPa) }\end{array}$ & 51.20 & 55.26 & 52.17 & 61.42 \\
\hline $\begin{array}{c}\text { Elongation at } \\
\text { break(\%) }\end{array}$ & 3.5 & 13.5 & 6.0 & 9.9 \\
\hline
\end{tabular}

As is shown in table 1, the tensile strength and elongation at break of PLA/Clay composites increase apparently modified with titanium ester, silane coupling agent and alkylamine. Among the three surface treatment agents, titanium ester has the best modification effect.

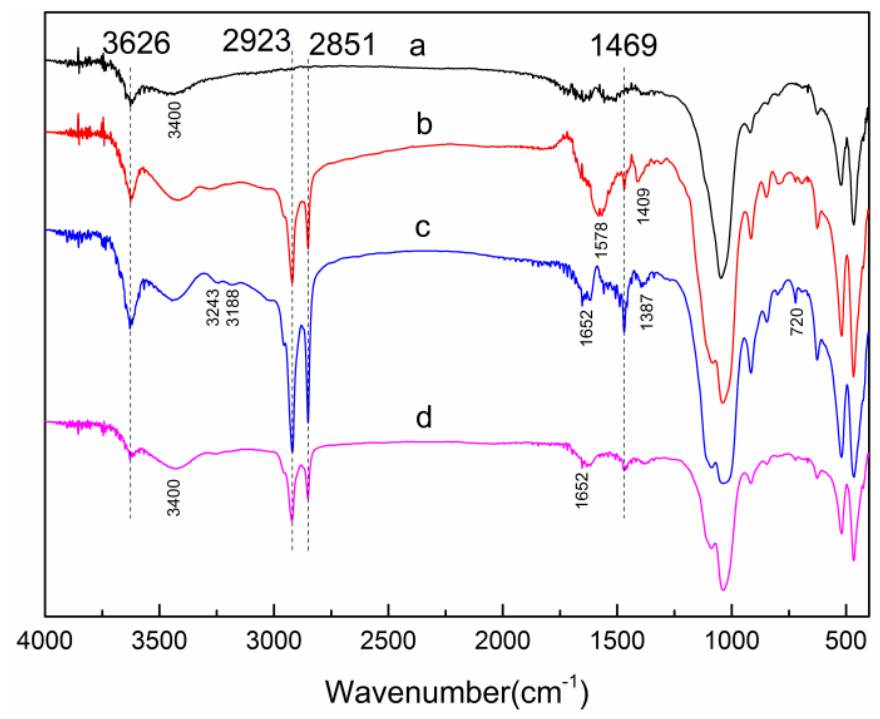

Fig. 1. FT-IR spectra of different samples: (a) pure clay; (b) clay/silane coupling agent; (c) clay/alkylamine;

(d) clay/titanium ester.

In order to ascertain the treatment effect, FT-IR measurements were carried out on the samples of pure clay and clay with different surface treatment agents. Fig. 1 shows the FT-IR spectra of pure clay ,clay/silane coupling agent, clay/alkylamine and clay/titanium ester, respectively.It can be seen from the infrared spectrum of pure clay that Si-O-Si stretching vibration absorption are at $1042 \mathrm{~cm}^{-1}$. For clay modified with different treatment agents the absorption bands at 2923 and $2851 \mathrm{~cm}^{-1}$ signify $\mathrm{CH}_{2}$ stretching, and the bands at 1469 and $720 \mathrm{~cm}^{-1}$ correspond to the bending and rocking vibration of $\mathrm{CH}_{2}$, respectively. From the Fig.1(b), the charateristic absorption bands of ammonia are observed at 1578 and $1409 \mathrm{~cm}^{-1}$. Fig. 1(c) shows the vibration bands at 3243 and $3188 \mathrm{~cm}^{-1}$ for $\mathrm{NH}_{4}{ }^{+}$stretching, $1387 \mathrm{~cm}^{-1}$ due to $\mathrm{C}-\mathrm{N}$ streching, at the $720 \mathrm{~cm}^{-1}$ for $\mathrm{CH}_{2}$ bending, $1652 \mathrm{~cm}^{-1}$ for crystal water bending. As shown in Fig. 1(d), The absorption bounds intensity of $\mathrm{O}-\mathrm{H}$ stretching $\left(3628 \mathrm{~cm}^{-1}\right)$ and $\mathrm{H}_{2} \mathrm{O}$ stretching $\left(3400 \mathrm{~cm}^{-1}\right)$ are reduced by comparing Fig. 1(a), this means that the hydrophile of modified clay are decreased.

These showed surface treatment agents dispersed well on the surface of the clay can be coupled with each other by the chemical bonds. Because the amino groups of alkylamine and silane coupling agent can react with the ester groups to break the molecular chains, the modified effect of 
the titanium ester was stronger than the two other modifiers. These results agree well with the mechanical properties results (as shown in Table 1).

In order to study the flowability, the melting indexs of the samples are shown in Table 2 . The three kinds of modifiers can play a connection role between clay and PLA, and improve the binding capacity of the interface and the intermolecular forces. With the increase of the friction resistance, the movement of the molecular chain is severely restricted, therefore, the mobility of the material is reduced.

Table 2 the melting index of the samples were modified by different surface treatment agents

\begin{tabular}{|c|c|}
\hline Types & Melting index $(\mathrm{g} / 10 \mathrm{~min})$ \\
\hline No treatment agent & 6.18 \\
\hline Alkylamine & 4.98 \\
\hline Silane coupling agent & 4.50 \\
\hline Titanium ester & 4.78 \\
\hline
\end{tabular}

DSC curves are shown in Fig. 2, whereas $\mathrm{T}_{\mathrm{g}}, \triangle \mathrm{H}_{\mathrm{m}}$, Crystallinity and $\mathrm{T}_{\mathrm{m}}$ are listed in Table 3. The Glass transition temperature of clay/PLA composites modified with titanium ester showed little change, but the crystallizability and crystallinity were increased a little. This showed that the silica has played the role of heterogeneous nucleation.

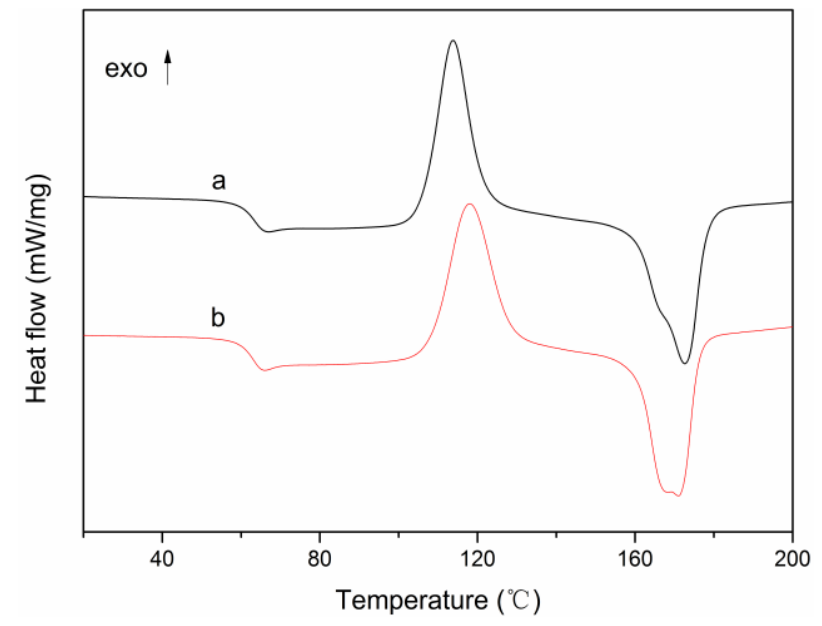

Fig. 2 The heating DSC thermograms: a. 3 wt.\% clay; b. 3 wt.\% clay/titanium ester

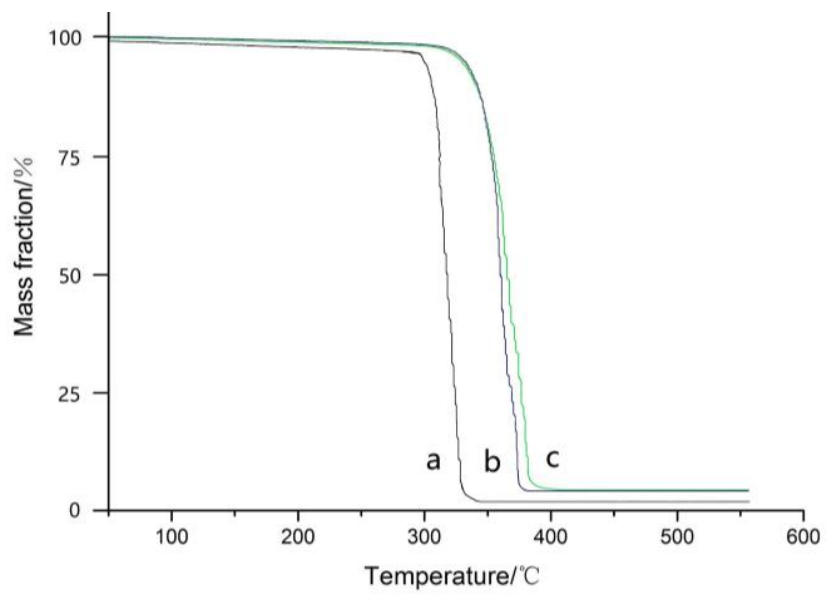

Fig. 3. The TG curves:a. pure PLA; b. 3 wt. $\%$ clay;c. 3 wt.\% clay/titanium ester

The TG curves are shown in Fig. 3, whereas the initial weight loss temperature and the maximum weight loss temperature are listed in Table 4. The results of TG showed clay/PLA composites modified with titanium ester began to lose weight at $303^{\circ} \mathrm{C}$, the thermal stability and heat resistance of composites increased obviously. When the layer structure of silicate is dispersed in the matrix of poly lactic acid, the path of the gas and the volatile decomposition products through the matrix are extended by the silicate layer which have an obvious barrier effect. Therefore, the thermal stability 
of poly lactic acid was greatly improved.

Table 3 the result of DSC

\begin{tabular}{|c|c|c|c|c|}
\hline Types & $\mathrm{T}_{\mathrm{g}}\left({ }^{\circ} \mathrm{C}\right)$ & $\mathrm{T}_{\mathrm{m}}\left({ }^{\circ} \mathrm{C}\right)$ & $\Delta \mathrm{H}_{\mathrm{m}}(\mathrm{J} / \mathrm{g})$ & Crystallinity $(\%)$ \\
\hline 3 wt.\% clay & 62.8 & 172.7 & 29.43 & 31.6 \\
\hline 3 wt.\% clay/titanium ester & 63.0 & 173.2 & 32.38 & 34.8 \\
\hline
\end{tabular}

Table 4 the result of TG

\begin{tabular}{|c|c|c|}
\hline Types & $\begin{array}{c}\text { The initial weight loss } \\
\text { temperature }\left({ }^{\circ} \mathrm{C}\right)\end{array}$ & $\begin{array}{c}\text { The maximum weight loss } \\
\text { temperature }\left({ }^{\circ} \mathrm{C}\right)\end{array}$ \\
\hline pure PLA & 280 & 346 \\
\hline 3 wt.\% clay & 302 & 381 \\
\hline 3 wt.\% clay/titanium ester & 303 & 392 \\
\hline
\end{tabular}

In order to determine the structure and morphology of the samples, micropolariscope was examined on the samples and the results are shown in Fig. 4. From Fig. 4 (a), it can be seen that pure PLA mainly consists of big spherocrystals which exsit obvious interfaces among them. Stress concentration will occur on the interfaces, which will deteriorate mechanical properties of the sample. As shown in Fig. 4 (b), the spherocrystal size and crystalline rate of the sample with addition of $3 \mathrm{wt} \%$ clay can be reduced and accelerated, respectively. Consequently, the crystallization temperature and crystallinity can be enhanced. These results mainly because that more crystal nucleus can be produced in PLA matrix with addition of heterogeneous nucleation agent (clay). The spherocrystal size of the samples can be further reduced modified with different surface treatment agents, as shown in Fig. 4(c), (d) and (e).

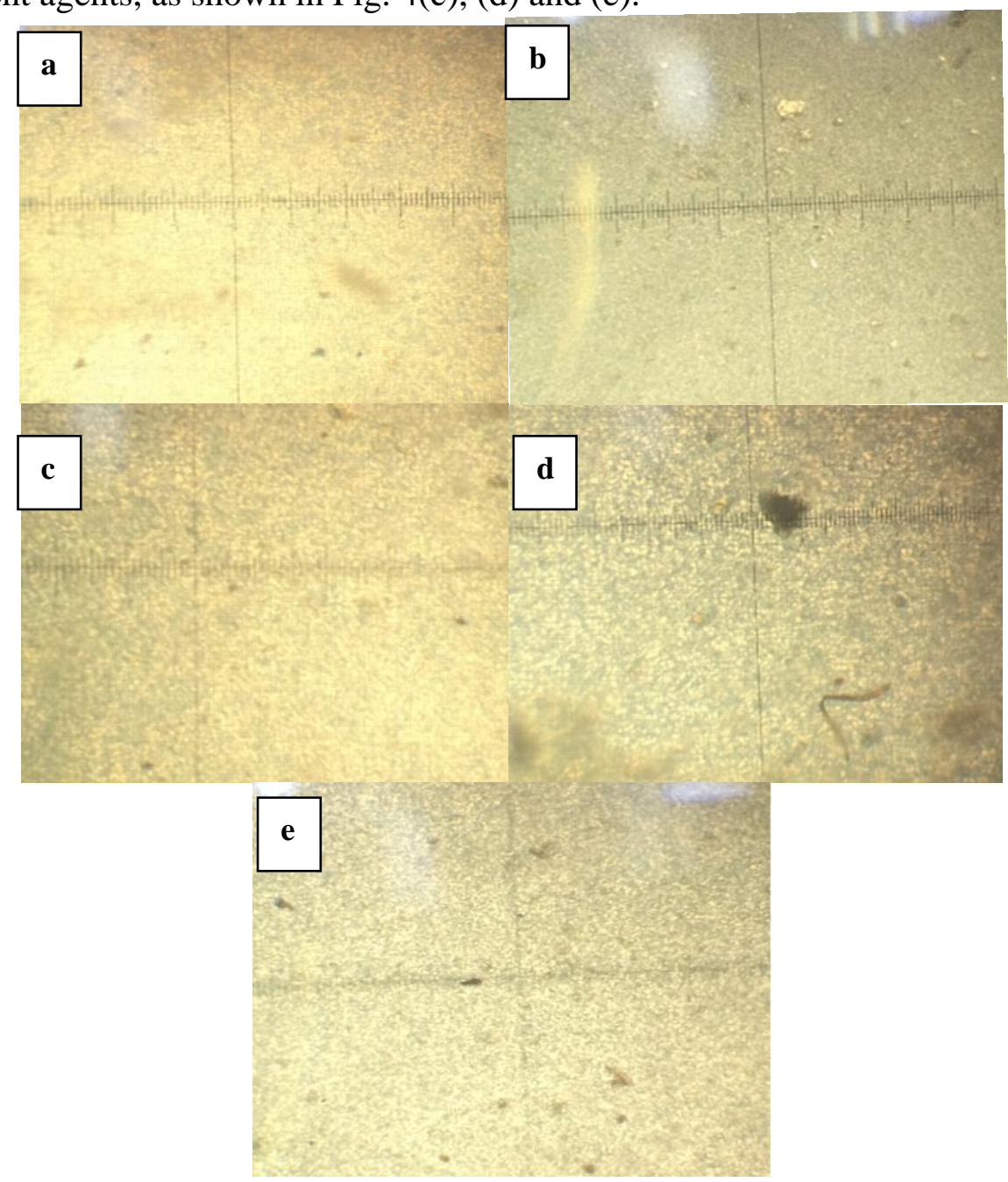

Fig.4. Micropolariscope micrographs of different samples $(100 \times)$ : (a) pure PLA; (b) 3 wt.\% clay; (c) 3 wt.\% clay/silane coupling agent; (d) $3 \mathrm{wt} . \%$ clay/Alkylamine;(e) $3 \mathrm{wt} . \%$ clay/Titanium ester 


\section{Conclusion}

(1)The tensile strength and elongation at break of PLA/clay composites was significantly increased after modification. With titanate modified composites tensile strength reached $61.2 \mathrm{MPa}$, $20 \%$ higher than the tensile strength of untreated material. compared with pure PLA, the tensile strength was improved by $26.7 \%$.

(2) The addition of clay played the role of heterogeneous nucleation, and improved the crystallinity and crystallization rate of PLA. It increased the heat resistance of PLA, which was further increased by titanium ester.

\section{Acknowledgement}

The above research work was supported by the Natural Science Foundation of China (21404032), the Science and Technology Talents Team Construction Projects of Zhengzhou City (131PCXTD615), the Development of Science and Technology Plan Projects of Zhengzhou City (20140771), the Funding Scheme for Young Teachers of Higher School in Henan Province (2014GGJS-062) and the Funding Projects of Henan University of Technology (2014JCYJ13).

\section{References}

[1] G.Z. Zhao. Research on L-lactic acid fermentation of potato [D]. Kunming, master dissertation at Kunming University of Science and Technology, 2012: 4-7.

[2] J. Ren, J.B. Li jianbo. PLA [M]. Beijing, Chemical Industry Publishing House, 2014, 8: 2-5.

[3] L. Shen, F. Qiao, Y.Q. Zhang. Mechanical properties and degradation properties in vitro of carbon fiber reinforced hydroxyapatite/polylactide composite [J]. Acta Materiae Compositae Sinica, 2007, 24 (5): 61-65 (in Chinese).

[4] S.S. Zhao, L. Yuan, H.L. Cao, et al. Preparation and Characteristics of PLA/MMT Nanocomposites with microwave irradiation [J]. Material Engineering, 2012 (2): 5-8.

[5] Y.L. Cao, J.B. Yi, S.F. Yan. Recent Research Advance in Biodegradable Poly( lactic acid) ( PLA): Modification and Application [J]. Polymer Bulletin, 2006 (10): 90-97.

[6] L.P. Zheng, D. Li, Y.D. Zhang, et al. Research Progress in PLA/Inorganic nanocomposites Prepared by in-situ technology [J]. China Plastics, 2012, 26 (11): 8-13.

[7] L.Liu, Y.M. Jiang. Effects of attapulgite on crystallization and thermal stability properties of poly (lactic acid) [J]. Acta Materiae Compositae Sinica, 2013, 30 (2): 75-82.

[8] A. Sodergard, M. Stolt. Properties of Lactic Acid Based Polymers and Their Correlation with Composition [J]. Progress in Polymer Science, 2002, 27:1123-1163.

[9] W. Zhuang, H.J. Jia, Z. Wang, et al. Preparation of nano-attapulgite/polylactide composites by in situ polymerization [J]. Acta Materiae Compositae Sinica, 2010, 27 (4): 45-51.

[10] L.F. Yuan, W.J. Zhen, Y.E. Liu, et al. Properties of PLA/OMMT Nanocomposites Prepared by Melting Intercalation [J]. China Plastics, 2009, 23 (7): 34-38.

[11] Y.G. Hou.Ceramic Abrasives Manufacture [M]. Beijing: Chinese light industry press, 2010: 23.

[12] Y.X. Zhang, X. Liu, B.G. Liu, et al. Research Progress in Poly( lactic acid)/Layered Silicate Nanocomposites [J]. China Plastics, 2012, 26 (10): 1-15.

[13] C. Thellen, C. Orroth, D. Froio, et al. Influence of montmorillonite layered silicate on plasticized poly( L-lactide) Blown Films [J]. Ploymer, 2005, 46: 11716-11727.

[14] P.P Ma, X.D. Wang, B.G. Liu,et al.Study on Preparation and Foaming Extrusion Behavior of PLA/OMMT Nanocomposites [J]. China Plastics, 2011, 25 (4): 59-64.

[15] L. Urbanczyk, F. Ngoundjo, M. Alexandre, et al. Synthesis of polylactide/Clay nanocomposites by In Situ Intercalative Polymerization in Supercritic Carbon Dioxide [J]. European Polymer Journal, 2009, 45: 643-648. 